\title{
Clinical Manifestations and Comorbidities of SARS-Cov-2 Infection: A Descriptive Study Nearmeen M. Rashad ${ }^{*}$, Nevin F. Ibrahim ${ }^{1}$ \\ Department ${ }^{1}$ Internal Medicine, Faculty of Medicine, Zagazig University, Sharkia, Egypt \\ *Corresponding author: Nearmeen M. Rashad, Mobile: (+20) 01224248642, \\ E-mail: nrashad78@yahoo.com and n.rashad@zu.edu.eg.
}

\begin{abstract}
Background: Coronavirus disease 2019 (COVID-19) is a clinical syndrome caused by infection with severe acute respiratory syndrome coronavirus 2 (SARS-CoV-2). Patients with severe illness have an overactive immune system, which can damage organs other than the lungs.

Objective: The aim of this study was to assess the prevalence of clinical manifestations and comorbidities in SARSCoV-2 infected patients.

Patients and methods: This retrospective single-center observational study was conducted in the Tertiary Hospital, Internal Medicine Department, Faculty of Medicine, Zagazig University. This retrospective observational study was conducted on consecutive 370 patients with confirmed SARS-CoV-2 infection from May to September 2020.The diagnosis of the cases was confirmed using RT-PCR for detection of the viral RNA. Demographic characteristics, including underlying comorbidities, symptoms, signs, laboratory findings, chest CT scan and treatment measures were reported.

Results: According to this retrospective, single-center observational study, which was conducted on consecutive 370 patients with confirmed SARS-CoV-2 infection? The study involved 193 Egyptian males (52.1\%) and 177 Egyptian females (47.9\%) with COVID-19. The mean age was 40. $2 \pm 14.74$ years. The common symptoms of the COVID-19 patients at the onset of sickness were myalgia [355 (95.9\%)], fatigue [291 (78.6\%)], headache [235 $(63.5 \%)]$, fever [247 (66.8\%)], cough [213 (57.6.\%)], sputum production [201 (54.3\%)] and dyspnea [189 $(51.1 \%)]$.The most prevalent comorbidity were hypertension [142(38.4\%)] followed by diabetes [132 (35.6\%)].

Conclusion: The commonest clinical manifestations of confirmed cases of COVID-19 were myalgia, fatigue, headache, fever, and cough and the most prevalent comorbidities associated with COVID 19 patients were hypertension and diabetes.
\end{abstract}

Keywords: SARS-CoV-2, Diabetes, Comorbidity, Coronavirus.

\section{INTRODUCTION}

Coronavirus disease (COVID-19), which is caused by the severe acute respiratory syndrome coronavirus 2 (SARS-CoV-2), is a global pandemic disease that began in Wuhan, China, and swiftly spread to over 180 nations ${ }^{[1]}$. COVID-19 is a novel and understudied illness, with little information available. However, comorbidities were found to enhance the risk of infection in the instances that were found ${ }^{[2]}$. Coronaviruses can cause multiple system infections in various animals and mainly respiratory tract infections in humans, such as severe acute respiratory syndrome (SARS) and Middle East respiratory syndrome ${ }^{[3]}$.

The majority of individuals have little symptoms and a favourable prognosis. Few patients infected with 2019-nCoV have suffered severe pneumonia, pulmonary oedema, ARDS, or multiple organ failure thus far ${ }^{[4]}$. COVID-19 is more likely to cause severe sickness in People who have chronic obstructive pulmonary disease (COPD) or other respiratory diseases. In individuals with COPD, the probability of acquiring COVID-19 is reported to be 4-fold greater than in those without COPD ${ }^{[5]}$.

Egyptian Ministry of Health and Population $(\mathrm{MOH})$ issued a standardized guide for the diagnosis and management of COVID-19. According to this protocol, patients with COVID-19 infection are

classified on clinical bases into mild, moderate, severe, and critical cases ${ }^{[6]}$.

Finally, critical patients are those who fulfill one or more of the following criteria: (a) respiratory failure needing mechanical ventilation, (b) shock, or other organ failures needing ICU surveillance and treatment [7].

COVID-19 can affect anyone, and the disease can cause symptoms ranging from mild to very severe. Recent interesting study reported the clinical features of 41 confirmed patients with COVID 19 and established that $13(32 \%)$ of them had underlying diseases, including cardiovascular disease, diabetes, hypertension, and chronic obstructive pulmonary disease ${ }^{[8]}$.

Another recent research by Wang et al. ${ }^{[4]}$ stated that at 138 patients of COVID-19, they found that 64 (46.4\%) of them had comorbidities.

Importantly, patients admitted to the intensive care unit (ICU) had a greater rate of comorbidities (72.2\%) than patients who were not sent to the ICU $(37.3 \%)$. In this regard, comorbidities maybe risk factors for adverse outcomes. Assessing the 
prevalence of these chronic diseases is the basis for modifying complications in patients infected with SARS-CoV-2.

To the date of writing this study, there have been more than 155 million confirmed cases of COVID-19, including more than 3 million deaths, according to WHO reports. Regarding COVID-19 in Egypt, the number of cases increased to more than 170,000 cases by the end of April $2021^{[9]}$.

This study aimed to assess the prevalence of clinical manifestations and comorbidities in SARS$\mathrm{CoV}-2$ infected patients.

\section{PATIENTS AND METHODS}

This retrospective single-center observational study was conducted in the tertiary hospital, Internal Medicine Department, Faculty of Medicine, Zagazig University.

This retrospective observational study was conducted on consecutive 370 patients (193 males and 177 females) with confirmed SARS-CoV-2 infection during the period from May to September 2020. According to the WHO and Egyptian Ministry of Health and Population $(\mathrm{MOH})$ criteria, the cases were diagnosed using RT-PCR for detection of viral RNA (Cobas 6800 system-Roche) ${ }^{[10]}$.

Demographic characteristics, including sex, age, underlying comorbidities were recorded. We also reported symptoms, signs, laboratory findings and chest CT scan.

\section{Ethical approval:}

The study protocol was approved by the Ethical Committee of the Faculty of Medicine, Zagazig University (IRB no-6389). Informed written consent was obtained from each eligible patient who participated in the study.

\section{Statistical analysis}

The collected data were coded, processed and analyzed using the SPSS (Statistical Package for Social Sciences) version 22 for Windows ${ }^{\circledR}$ (IBM SPSS Inc, Chicago, IL, USA).

Data were tested for normal distribution using the Shapiro Walk test. Qualitative data were represented as frequencies and relative percentages. Chi square test $(\chi 2)$ to calculate difference between two or more groups of qualitative variables.

Quantitative data were expressed as mean \pm SD (Standard deviation). Independent samples t-test was used to compare between two independent groups of normally distributed variables (parametric data). $\mathrm{P}$ value $\leq 0.05$ was considered significant.

\section{RESULTS}

Demographical characteristics of the patients enrolled in this study:

According to this retrospective single-center observational study that was conducted on consecutive 370 patients with confirmed SARS-CoV-2 infection. The study involved 193 Egyptian males $(52.1 \%)$ and 177 Egyptian females (47.9\%) with COVID-19, their mean age was $40.2 \pm 14.74$ years.

The common symptoms of the COVID-19 patients at the onset of sickness were myalgia [355 (95.9\%)], fatigue [291 (78.6\%)], headache [235 (63.5\%)], fever [247 (66.8\%)], cough [213 (57.6.\%),sputum production [201 $(54.3 \%)$ and dyspnea [189 $(51.1 \%)]$ less common symptoms were nasal congestion, diarrhea, nausea, abdominal pain vomiting, anosmia, loss of taste ,eye congestion and sore throat (Table 1).

Table (1): Characteristics of patients with COVID-19

\begin{tabular}{|l|l|}
\hline \multicolumn{1}{|c|}{$\begin{array}{c}\text { Characteristics, } \\
\text { symptoms }\end{array}$} & \multicolumn{1}{|c|}{$\begin{array}{c}\text { Number and } \\
\text { percentage } \\
\text { (N=370) }\end{array}$} \\
\hline $\begin{array}{l}\text { Age, yr. } \\
\text { Mean } \pm \text { SD }\end{array}$ & $40.2 \pm 14.74$ \\
\hline $\begin{array}{l}\text { Sex } \\
\text { Male } \\
\text { Female }\end{array}$ & $\begin{array}{l}193(59.4 \%) \\
177(40.6 \%)\end{array}$ \\
\hline BMI, kg/m ${ }^{2}$ & $30.34 \pm 8.43$ \\
\hline Current smoker & $29 / 370(7.8 \%)$ \\
\hline Co morbidity & \\
\hline Any & $79(21.4 \%)$ \\
\hline Hypertension & $142(38.4 \%)$ \\
\hline Diabetes & $132(35.6 \%)$ \\
\hline Chronic liver disease & $69(18.6 \%)$ \\
\hline Chronic renal disease & $12(3.2 \%)$ \\
\hline Ischemic heart disease & $19(5.1 \%)$ \\
\hline Malignancy & $22(5.9 \%)$ \\
\hline COPD & $69(18.6 \%)$ \\
\hline Immunosuppression & $15(4.1 \%)$ \\
\hline Symptoms & $16(4.3 \%)$ \\
\hline Asymptomatic & $15(4.1 \%)$ \\
\hline Fever & $247(66.8 \%)$ \\
\hline Cough & $213(57.6 \%)$ \\
\hline Sputum production & $201(54.3 \%)$ \\
\hline Eye congestion & $10(2.7 \%)$ \\
\hline Dyspnea & $189(51.1 \%)$ \\
\hline Nasal congestion & $66(17.8 \%)$ \\
\hline Sore throat & $46(12.4 \%)$ \\
\hline Myalgia & $355(95.9 \%)$ \\
\hline Anosmia & $78(21.1 \%)$ \\
\hline Abdominal pain & $79(21.4 \%)$ \\
\hline Fatigue & $291(78.6 \%)$ \\
\hline Diarrhea & $80(21.6 \%)$ \\
\hline Nausea and vomiting & $82(22.2 \%)$ \\
\hline Headache & $235(63.5 \%)$ \\
\hline & \\
\hline
\end{tabular}


Laboratory characteristics of patients with COVID-19 on admission:

Laboratory characteristics of patients with confirmed and reported cases of COVID-19 (Table 2).

Table (2): Laboratory findings of patients with COVID-19

\begin{tabular}{|l|l|}
\hline \multicolumn{1}{|c|}{ Laboratory findings } & \multicolumn{1}{c|}{ Mean \pm SD } \\
\hline Leukocytes, $\times 10^{9} / \mathrm{L}$ & $9.7 \pm 2.7$ \\
\hline Neutrophils, $\times 10^{9} / \mathrm{L}$ & $67.5 \pm 6.1$ \\
\hline Lymphocytes $\times 10^{3} / \mu \mathrm{L}$ & $1.4 \pm 0.07$ \\
\hline Platelets, $\times 10^{3} / \mu \mathrm{L}$ & $198.4 \pm 7.7$ \\
\hline Hemoglobin, $\mathrm{g} / \mathrm{dL}$ & $11.8 \pm 1.11$ \\
\hline Alanine aminotransferase, $\mathrm{U} / \mathrm{L}$ & $38.5 \pm 3.2$ \\
\hline Aspartate aminotransferase, $\mathrm{U} / \mathrm{L}$ & $36.7 \pm 3.8$ \\
\hline Blood urea nitrogen, $\mathrm{mmol} / \mathrm{L}$ & $33.6 \pm 3.6$ \\
\hline Serum creatinine, $\mathrm{mg} / \mathrm{dL}$ & $1.7 \pm 0.09$ \\
\hline C-reactive $\mathrm{protein}, \mathrm{mg} / \mathrm{L}$ & $15.7 \pm 1.6$ \\
\hline D-dimer $(\mathrm{mg} / \mathrm{L})$ & $0.81 \pm 0.01$ \\
\hline Ferritin $(\mathrm{ng} / \mathrm{mL})$ & $387.6 \pm 48.7$ \\
\hline
\end{tabular}

\section{Radiographic findings of patients with COVID-19 on admission:}

The prevalence of normal finding in both $\mathrm{x}$ ray and CT chest finding was $22(5.9 \%)$ and regarding pneumonia, the prevalence of unilateral pneumonia was $31(8.4 \%)$ and for bilateral pneumonia was $69(18.6 \%)$. Also, ground glass opacity prevalence was 65 (17.8\%) and lastly crazy paving prevalence was 14 (3.7\%) (Table 3 and figure 1).

Table (3): Radiographic findings of patients with COVID-19

\begin{tabular}{|l|l|}
\hline Chest $\mathrm{x}-$ ray/CT findings & Number and percentage \\
\hline Normal & $22(5.9 \%)$ \\
\hline Unilateral pneumonia & $31(8.4 \%)$ \\
\hline Bilateral pneumonia & $69(18.6 \%)$ \\
\hline Ground-glass opacity & $65(17.6 \%)$ \\
\hline Crazy paving & $14(3.7 \%)$ \\
\hline
\end{tabular}




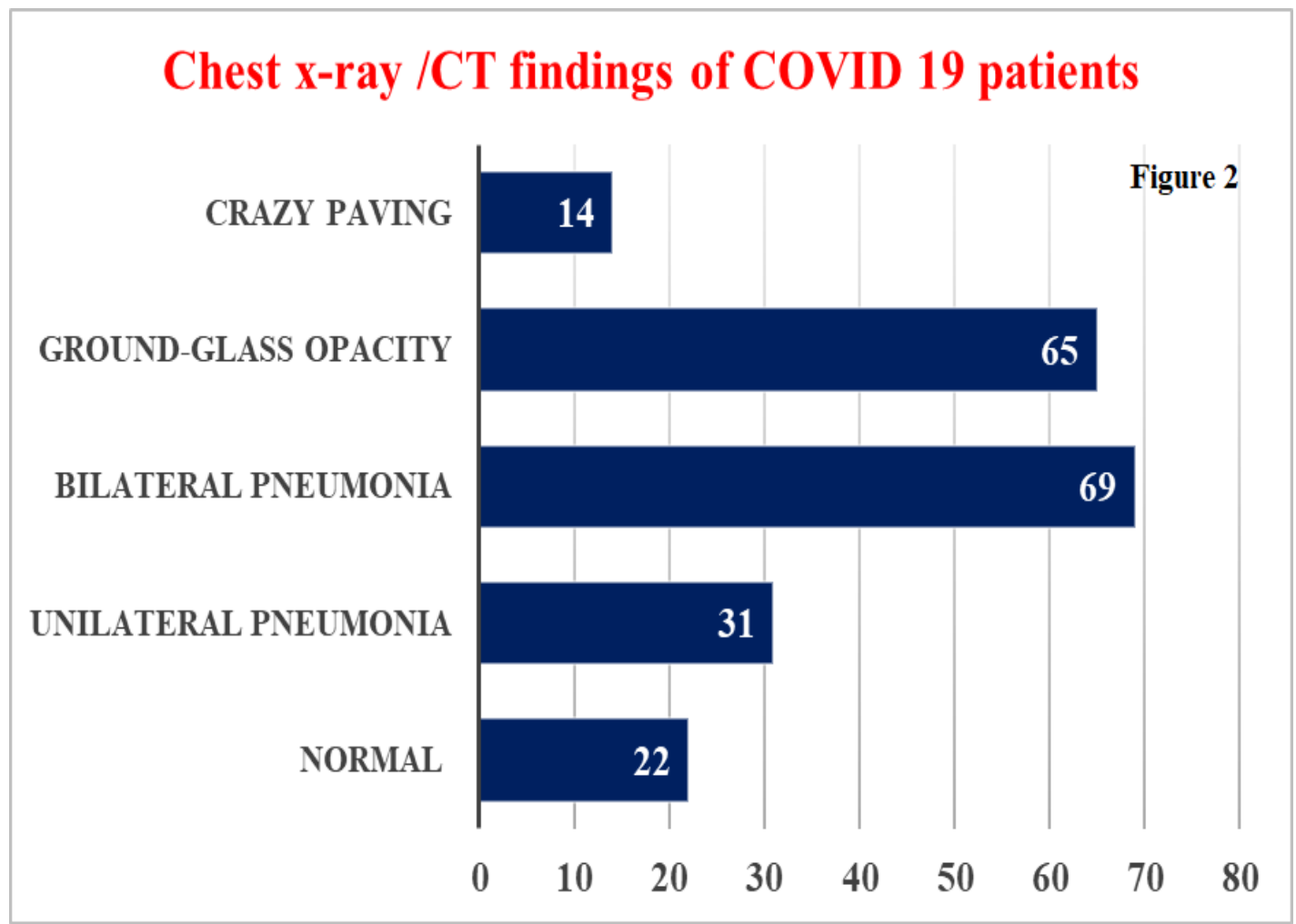

Figure (1): Radiographic findings of patients with COVID-19 on admission.

\section{The prevalence of comorbidities among studied patients with COVID 19}

According to the current study results the prevalence of COVID-19 comorbidities, as shown in table (1I and figure (2), the most common comorbidities identified in these patients were hypertension [142 (38.4\%)] and diabetes [132 (35.6\%)]. The less common comorbidities were COPD, chronic liver disease, chronic renal disease, ischemic heart disease, malignancy as well as patients on immunosuppression.

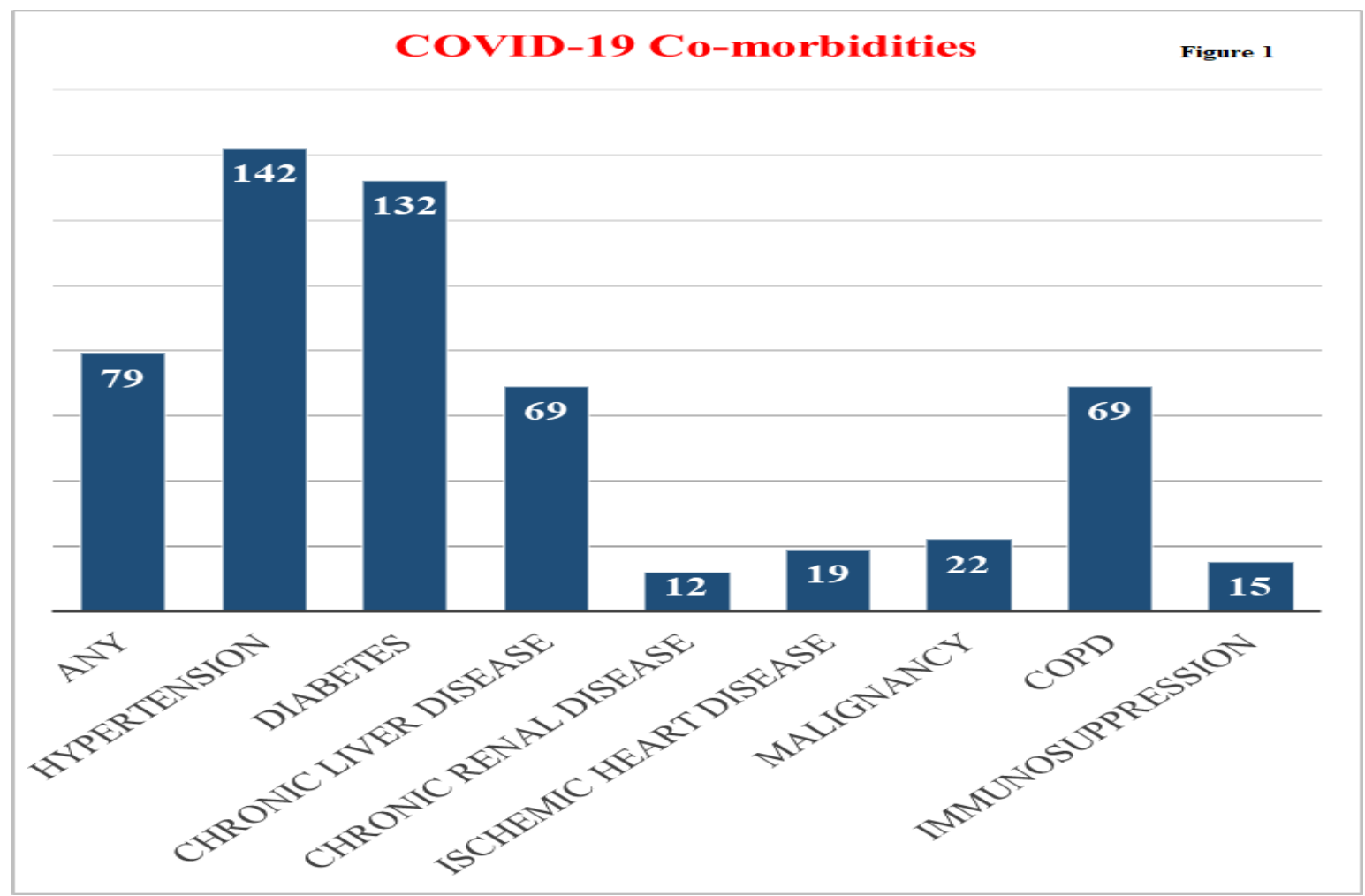

Figure (2): The prevalence of comorbidities among studied patients with COVID 19. 


\section{DISCUSSION}

More interesting, recently published studies reported that SARS-CoV-2 virus can affect all individuals irrespective of age, gender, and ethnicity, but to varying degrees [11]. According to the current study results among 370 Egyptian patients with COVID 19, the prevalence of males was $52.1 \%$ and prevalence for females was $47.9 \%$ and their mean age was $40.2 \pm 14.74$ years.

Another Egyptian study was conducted on sample of ESNA Quarantine Hospital's patients, observed that the mean age of patients was $55.5 \pm 10.1$ and male prevalence was $77.8 \%$ that was more common than female $(22.2 \%)$ in mild to moderate $(\mathrm{n}=$ 36). However, in severe/critical group in the same study the mean age of patients was $62.6 \pm 10.1$ years and male prevalence was $66.7 \%$ that was more common than female (33.3\%) ${ }^{[12]}$. The difference between our study results and ESNA results is due to different study sample size and time of the study as this study was conducted early in the pandemic.

Regarding the clinical manifestation of COVID 19 patients, the current study observed that the most common manifestations were myalgia [355 (95.9\%)], fatigue [291 (78.6\%)], headache [235 (63.5\%)], fever [247 (66.8\%)] and cough [213 (57.6\%)]. According to Ghweil $\boldsymbol{e t}$ al. ${ }^{[12]}$ the commonest manifestations were fever $(83.3 \%)$, dry cough $(47.2 \%)$ and dyspnea (42.4\%). Most COVID-19 cases remain asymptomatic or present with relatively mild flu-like symptoms, increasing the risk of transmission and the significant spread of SARS-CoV-2 ${ }^{[13]}$.

As stated above, SARS-CoV-2 infects people of all age groups, but individuals aged above 60 years, along with comorbidities such as diabetes, COPD, and cardiovascular diseases, are at a higher risk of developing infection ${ }^{[14]}$. According to the current study results, the prevalence of co morbidities were hypertension [142 (38.4\%)], diabetes [132 (35.6\%)], and the least common comorbidities were COPD, chronic liver disease, chronic renal disease, ischemic heart disease, malignancy as well as patients on immunosuppression.

Growing evidence highlights the ability of SARS-CoV-2 to infect and damage multiorgan systems is dependent on the expression/distribution pattern of the host angiotensin-converting enzyme 2 receptor $(\mathrm{ACE} 2)^{[15,16]}$.

Concerning the role of comorbidities, such as diabetes and obesity in increasing the severity of COVID 19, they up regulate ACE2, leading to an increase in viral load within various tissues and organs. Furthermore, in diabetic and obese patients, increased ACE2 shedding from the cell surface promotes ACE2 redistribution in the body and accumulation in the lungs ${ }^{[17]}$. According to Kumar $\boldsymbol{e t}$ al. ${ }^{[18]}$, a reduction in the baseline expression of ACE2 in the vasculature in diabetic and obese persons causes endothelial dysfunction, which contributes to the increased incidence of thrombotic events in COVID19 patients.

As regards the prevalence of normal finding in both $\mathrm{x}$ ray and CT chest findings, they were $22(5.9 \%)$ and regarding pneumonia, the prevalence of unilateral pneumonia was $31(8.4 \%)$ and that of bilateral pneumonia was $69(18.6 \%)$. Also, ground glass opacity prevalence was $65(17.8 \%)$ and lastly crazy paving prevalence was 14 (3.7\%). Ghweil et al. ${ }^{[12]}$ reported that the radiological finding was variable according to severity of COVIDS 19 infection.

\section{CONCLUSION}

The commonest clinical manifestations of confirmed cases of COVID-19 were myalgia, fatigue, headache, fever, and cough and the most prevalent comorbidities associated with COVID 19 patients were hypertension and diabetes.

Declaration of Competing Interest: The authors declare that they had no known competing financial interests.

\section{ACKNOWLEDGMENTS}

We thank all the patients for their agreement to participate in this study. We also thank the COVID-19 clinical team of Zagazig University Hospitals for help in collecting.

\section{REFERENCES}

1. Singh A, Gupta R, Ghosh A et al. (2020): Diabetes in COVID-19: prevalence, pathophysiology, prognosis, and practical considerations. Diabetes Metab Syndr Clin Res Rev., 14 (4): 303-10.

2. Maragakis L (2020): Coronavirus symptoms: frequently asked questions. Johns Hopkins Medicine.https://www.hopkinsmedicine.org/health/co nditions-and-diseases/coronavirus/coronavirussymptoms-frequently-asked-questions].

3. Garg S, Kim L, Whitaker $M$ et al. (2020): Hospitalization rates and characteristics of patients hospitalized with laboratory-confirmed coronavirus disease 2019 - COVID-NET, 14 states, March 1-30, 2020. Centers for Disease Control and Prevention: MMWR., 69 (15): 458-464.

4. Wang D, Hu B, Hu C et al. (2020): Clinical characteristics of 138 hospitalized patients with 2019 novel coronavirus-infected pneumonia in Wuhan, China. JAMA., 323 (11): 1061-1069.

5. Paudel S (2020): A meta-analysis of 2019 novel coronavirus patient clinical characteristics and comorbidities.

https://www.researchsquare.com/article/rs-21831/v1].

6. CDC (2020): Coronavirus (COVID-19): symptoms of coronavirus. Centers for Disease Control and Prevention. https://www.cdc.gov/coronavirus/2019ncov/symptoms-testing/ symptoms.html 
7. Medhat M, Kassas M (2020): COVID-19 in Egypt: Uncovered figures or a different situation? J Glob Health, 10 (1): 010368.

8. Huang C, Wang Y, Li X et al. (2020): Clinical features of patients infected with 2019 novel coronavirus in Wuhan, China. Lancet, 395 (10223): 497-506.

9. WHO (2020): Covid19. Available from: https://covid19.who.int/region/emro/country/eg

10. WHO (2020): Clinical Management of Severe Acute Respiratory Infection (SARI) When COVID-19 Disease is Suspected: Interim Guidance, 13 March 2020. World Health Organization; 2020. https://apps.who.int/iris/handle/10665/331446

11. Chakravarty D, Nair SS, Hammouda $\mathrm{N}$ et al. (2020): Sex differences in SARS-CoV-2 infection rates and the potential link to prostate cancer. Commun Biol., 3: 374-85.

12. Ghweil A, Hassan M, Khodeary A et al. (2020): Characteristics, Outcomes and Indicators of Severity for COVID-19 Among Sample of ESNA Quarantine Hospital's Patients, Egypt: A Retrospective Study. Infect Drug Resist., 13: 2375-2383.
13. Oran D, Topol E (2021): The proportion of SARS$\mathrm{CoV}-2$ infections that are asymptomatic. Ann Intern Med., 20: 1-8.

14. WHO (2020): Coronavirus disease 2019 (COVID-19) Situation report - 141. Geneva, Switzerland. https://www.who.int/docs/defaultsource/coronaviruse/situation-reports/20200609covid-19-sitrep-141.pdf?sfvrsn=72fa1b16.

15. Hoffmann M, Kleine-Weber $\mathrm{H}$, Schroeder $\mathrm{S}$ et al. (2020): SARS-CoV-2 cell entry depends on ACE2 and TMPRSS2 and is blocked by a clinically proven protease inhibitor. Cell, 181: 271-280.

16. Ashraf U, Abokor A, Edwards J et al. (2020): SARSCoV-2, ACE2 expression, and systemic organ invasion. Physiol Genomics, 53: 51-60.

17. Kruglikov I, Shah $M$, Scherer $P$ (2020): Obesity and diabetes as comorbidities for COVID-19: Underlying mechanisms and the role of viral-bacterial interactions. eLife, 9: 61330.

18. Kumar A, Narayan $R$, Kumari $C$ et al. (2020): SARS-CoV-2 cell entry receptor ACE2 mediated endothelial dysfunction leads to vascular thrombosis in COVID-19 patients. Med Hypotheses, 145:110320. 